\title{
ISG15 predicts poor prognosis and promotes cancer stem cell phenotype in nasopharyngeal carcinoma
}

\author{
Ren-Hui Chen ${ }^{1, *}$ Yong Du', ${ }^{2}$, Ping Han ${ }^{1}$, Hong-Bo Wang ${ }^{2}$, Fa-Ya Liang ${ }^{1}$, Guo-Kai \\ Feng $^{2}$, Ai-Jun Zhou ${ }^{2}$, Mu-Yan $\mathrm{Cai}^{3}$, Qian Zhong ${ }^{2}$, Mu-Sheng Zeng' ${ }^{2}$, Xiao-Ming Huang ${ }^{1}$ \\ ${ }^{1}$ Department of Otolaryngology-Head and Neck Surgery, Guangdong Provincial Key Laboratory of Malignant Tumor \\ Epigenetics and Gene Regulation, Medical Research Center, Sun Yat-sen Memorial Hospital, Sun Yat-sen University, \\ Guangzhou, 510120, China \\ ${ }^{2}$ Department of Experimental Research, State Key Laboratory of Oncology in South China, Collaborative Innovation Center \\ for Cancer Medicine, Sun Yat-sen University Cancer Center, Guangzhou 510060, China \\ ${ }^{3}$ Department of Pathology, State Key Laboratory of Oncology in South China, Collaborative Innovation Center for Cancer \\ Medicine, Sun Yat-sen University Cancer Center, Guangzhou 510060, China \\ "These authors have contributed equally to this work \\ Correspondence to: Xiao-Ming Huang, e-mail: hxming@mail.sysu.edu.cn \\ Mu-Sheng Zeng, e-mail: zengmsh@sysucc.org.cn \\ Keywords: interferon-stimulated gene 15, nasopharyngeal carcinoma, prognosis, cancer stem cell \\ Received: October 09, $2015 \quad$ Accepted: February 06, $2016 \quad$ Published: February 23, 2016
}

\section{ABSTRACT}

Interferon-stimulated gene 15 (ISG15), the first identified ubiquitin-like protein, is known for its anti-viral capacity. However, its role in tumorigenesis remains controversial. Here, using RNA-seq profiling analysis, we identified ISG15 as a differentially expressed gene in nasopharyngeal carcinoma (NPC) and validated its overexpression in NPC samples and cells. High ISG15 levels in NPC tissues were correlated with more frequent local recurrence and shorter overall survival and disease-free survival. ISG15 overexpression promoted a cancer stem cell phenotype in NPC cells, including increased colony and tumorsphere formation abilities, pluripotency-associated genes expression, and in vivo tumorigenicity. By contrast, knockdown of ISG15 attenuated stemness characteristics in NPC cells. Furthermore, overexpression of ISG15 increased NPC cell resistance to radiation and cisplatin (DDP) treatment. Our study demonstrates a protumor role of ISG15, and suggests that ISG15 is a prognostic predictor and a potential therapeutic target for NPC.

\section{INTRODUCTION}

Nasopharyngeal carcinoma (NPC) is a prevalent disease in Southern China and Southeast Asia [1]. Despite the improved survival of NPC patients with advances in treatment techniques, such as radiotherapy and a combination of chemotherapy, the prognosis of advanced stages is less favorable [2,3]. Locoregional recurrence and distant metastases remain the major etiology of mortality in NPC patients [4-6]. Therefore, identifying diagnostic markers and therapeutic targets for NPC is a novel management strategy in the era of genomics. Using RNAseq profiling analysis, we identified Interferon Stimulated Gene 15 (ISG15) as one of the differentially expressed genes in NPC. ISG15 is the first identified ubiquitin-like protein that is conjugated to cellular substrates to form ISGylated proteins and shows antiviral and anti-bacterial activities [7-
11]. Recent studies have reported that ISG15 is frequently overexpressed in various cancers [12-15]. Unlike its definite anti-viral capacity, the role of ISG15 in tumor development remains controversial. In cancer cells, ISG15 exists in two forms: free (intracellular) and conjugated to cellular proteins (ISGylation) [16]. Intracellular ISG15 exhibits protumor capacities such as promotion of the proliferation and migration of cancer cells $[12,14,15,17]$. However, it has also been reported that ISGytion attenuates the HIF1a mediated tumorigenic growth [18] and suppresses lung cancer growth by targeting cyclin D1 [19]. In addition to the intracellular system, free ISG15 is also secreted into the extracellular milieu and acts as an immunomodulatory cytokine in the tumor microenvironment [13,20]. It has been reported that tumor-associated macrophages (TAMs) secrete ISG15, which enhances cancer stem cell (CSC) phenotypes in pancreatic ductal adenocarcinoma [13]. While Burks 
and colleagues have demonstrated extracellular free ISG15 triggers an antitumor immune response and suppresses breast cancer growth [20]. Therefore, whether ISG15 is a tumor promoter or a tumor suppressor has not yet been fully established.

In the present study, we showed that ISG15 was markedly overexpressed in NPC. Increased ISG15 expression was correlated with tumor recurrence and poor prognosis, which could be due to its capacity to promote CSC phenotype and radioresistance and chemoresistance in NPC. Our findings provide new insight into the role of ISG15 in NPC tumorigenesis and suggest that ISG15 might be a potential therapeutic target for NPC.

\section{RESULTS}

\section{ISG15 was identified as a potential differentially expressed gene in NPC through RNA-Seq}

To investigate genes capable of conferring tumorigenesis in NPC, we selected a panel of nine patients' nasopharyngeal biopsy specimens and one primary cultured nasopharyngeal epithelial cell (NPEC03) for RNA-Seq analysis. ISG15 was identified as one of the differentially expressed genes in NPC. To validate the RNA-Seq data, qRT-PCR and Western blotting were performed to detect ISG15 expression in two cohorts of NPC biopsy specimens and noncancerous nasopharyngeal epithelium specimens, and NPC cell lines as well as immortalized nasopharyngeal epithelial cell lines (NPECs). We demonstrated that ISG15 mRNA was significantly up-regulated in tumor tissues (Figure 1A). These results were consistent with Dodd's outcome from the publically available microarray GEO dataset (Figure 1B, http://www.ncbi.nlm.nih.gov/ sites/GDSbrowser?acc=GDS3341). In addition, ISG15 mRNA and protein levels were elevated in multiple NPC cell lines, such as SUNE2, 6-10B, S26, CNE1, CNE2, HNE1 and HONE1, compared with immortalized NPECs, NPEC1-Bmil and NPEC2-Bmil (Figure 1C and 1D). Taken together, these observations confirmed that ISG15 is highly expressed in NPC.
A
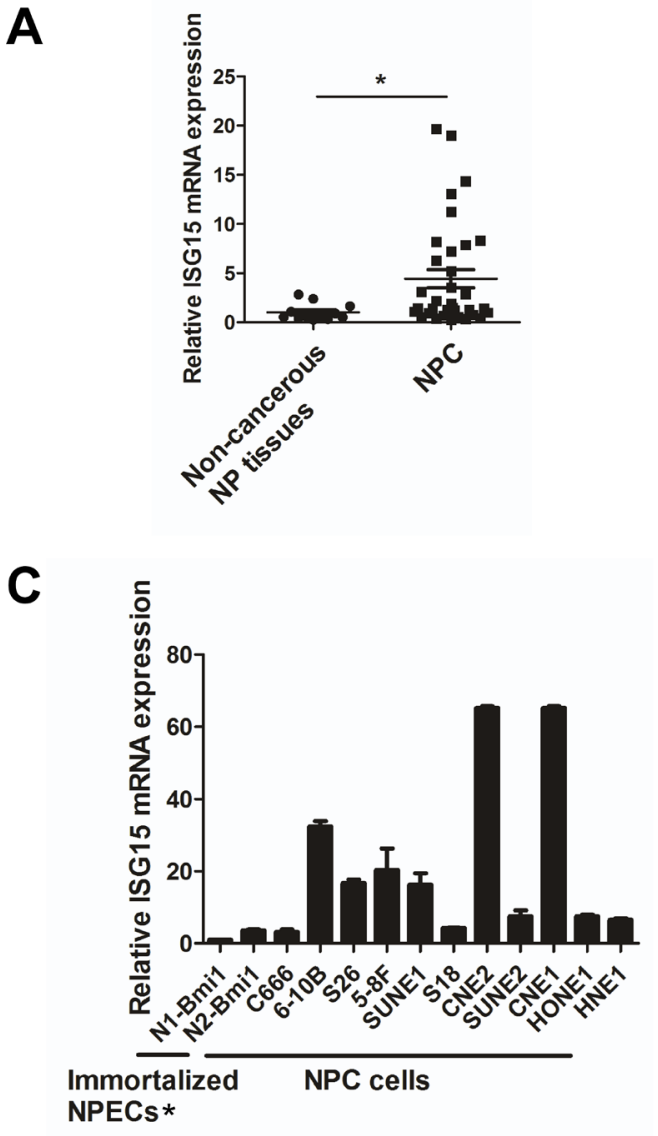

B

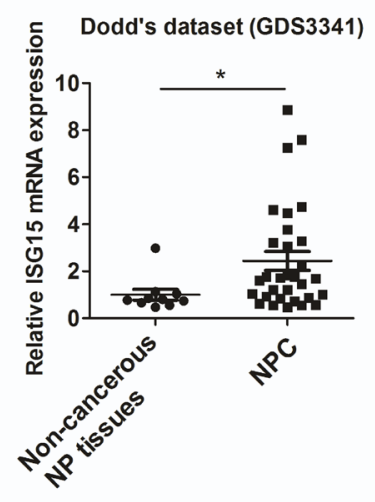

D

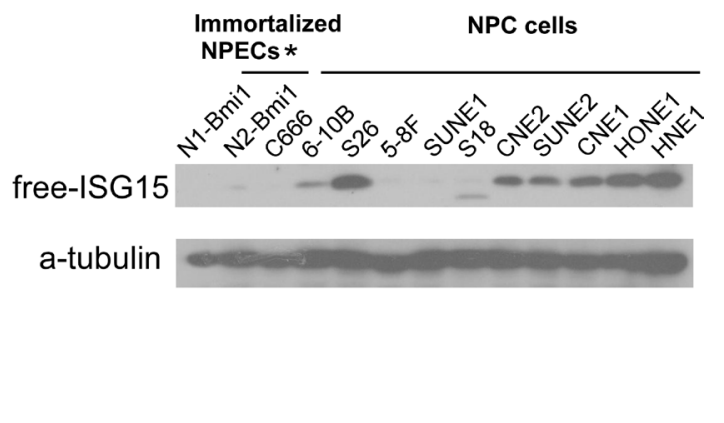

Figure 1: Up-regulation of ISG15 expression in NPC sample and cell lines. A. Expression of ISG15 mRNA was detected by RT-PCR in NPC and NP mucosa samples. B. Expression of ISG15 mRNA from Dodd's dataset for NPC versus NP mucosa samples. C. ISG15 mRNA expression and D. protein level in NPC cell lines and immortalized NPECs. * Immortalized NPECs, NPEC1-Bmi1 and NPEC2-Bmil, have been abbreviated as N1-Bmi1 and N2-Bmil. 


\section{High expression of ISG15 predicted more frequent recurrence in NPC}

To examine the whether the high expression of ISG15 protein is correlated with the clinical progression of NPC, IHC was performed in an independent formalinfixed, paraffin-embedded-based (FFPE-based) tissue microarray (TMA) consisting of 209 NPC samples. Excluding the seven shedding chips, 197 of 202 (97.5\%) cases showed primary cytoplasmic staining of ISG15 in cancer cells, with occasional immunoreactivity observed in the stromal lymphocytes (Figure 2). The ROC curve analysis for survival status was used to determine the cutoff score for high expression of ISG15. Tumors with scores above 5 were considered to have high ISG15 expression, leading to the greatest number of tumors classified as having or not having the clinical outcome. In our study, high ISG15 levels were detected in 63/202 $(31.2 \%)$ of NPCs. The results showed no significant association between ISG15 expression and patient gender, age, histological classification, T classification, $\mathrm{N}$ classification, distant metastasis and clinical stages $(P>0.05$, Table 1). Whereas, ISG15 expression was correlated with tumor recurrence because high expression of ISG15 was more frequent in the NPC recurrence group than in the non-recurrence group $(P<0.05$, Table 1$)$.

\section{High expression of ISG15 indicated a shorter overall survival and disease-free survival in NPC}

For the 202 patients in this study, the median followup period was 73 months (range, 3 to 233 months), with 76 cancer-related deaths at the final clinical follow-up. The 5 -year overall survival rate was $64 \%$ for the total study population. Kaplan-Meier analysis demonstrated that the patients with high ISG15 expression had significantly shorter overall survival (OS) than patients with low ISG15 expression (99.4 months vs. 166.3 months, $P=0.010$, Figure 3A). Moreover, the disease-free survival (DFS) in patients with high expression of ISG15 protein was shorter than the survival in patients with low expression of ISG15 (93.6 months vs. 166.8 months, $P=0.012$, Figure 3B). Further analysis with a Cox proportional hazards model was performed to determine whether ISG15 expression could serve as an independent prognostic predictor. A series of factors, including patients' gender, age, histological classification, $\mathrm{T}$ classification, $\mathrm{N}$ classification, clinical stages, distant metastasis, and ISG15 expression level, were included in the univariate Cox regression analysis to test their association with the OS of NPC patients. The variables most significantly associated with OS in the univariate analysis were further analyzed by multivariate analysis. The multivariate analysis model showed that ISG15 expression (HR, 1.790; 95\% CI. 1.113$2.880 ; P=0.016)$ and clinical stage (HR, $2.386 ; 95 \% \mathrm{CI}$ $1.228-4.636 ; P=0.010$ ) were the predominant independent predictors of OS as shown in Table 2.

Since the survival is usually markedly shorter in stage IV as compared with stage I-III, we performed the survival analysis concerning the ISG15 expression in stage I-III and stage IV. As shown in Figure 3C and 3D, the survival curves were separated and there were a tendency for reduced survival with high ISG15 expression in stage I-III (112.2 months vs. 188.9 months, $P=0.058)$ and stage IV (48.2 months vs. 69.8 months, $P=0.23$ ) during a longterm follow-up. Consequently, we further analyzed the survival with 5-year and 3-year follow-up. The patients with high expression of ISG15 had a significant shorter
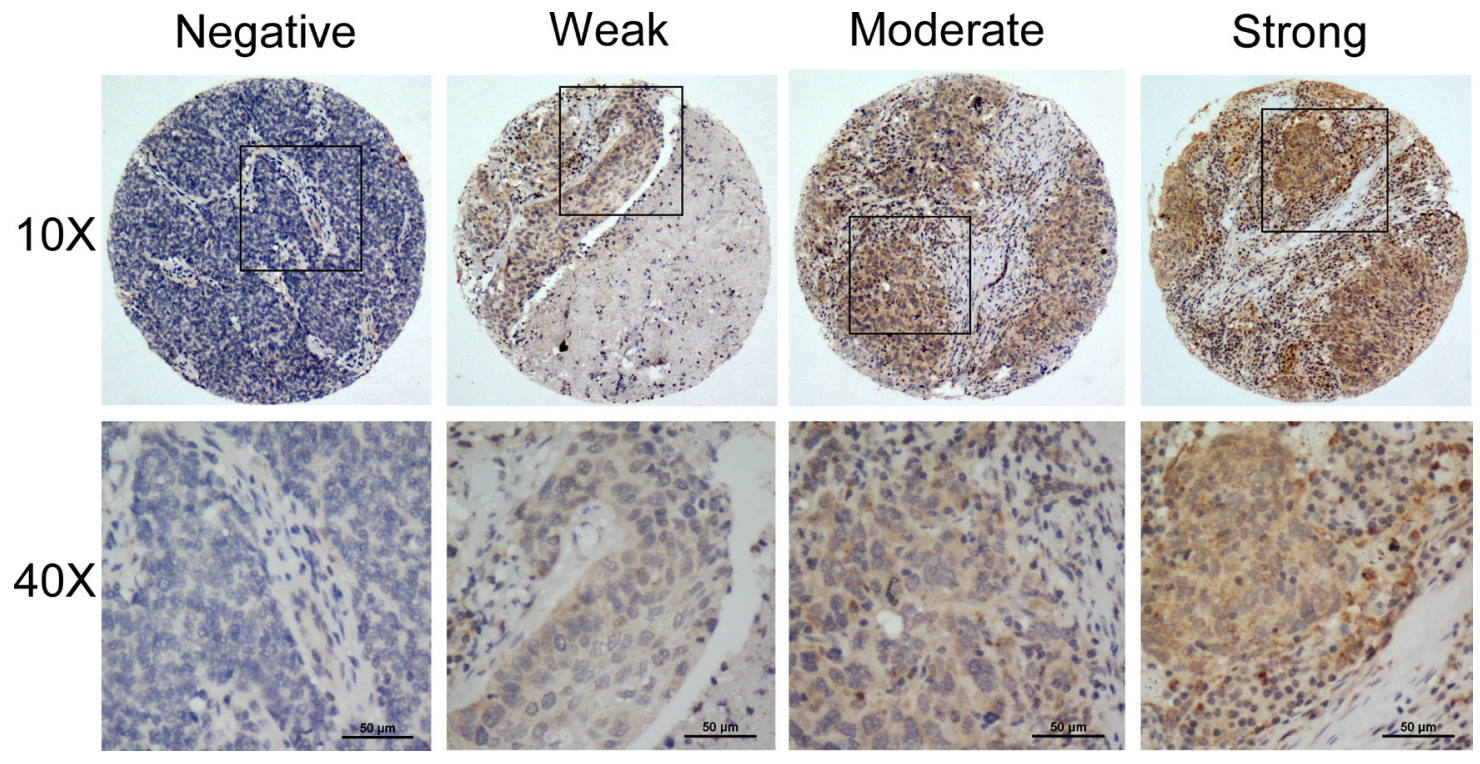

Figure 2: Representative IHC staining of ISG15 in NPC samples. 
Table 1: Correlation between the expression of ISG15 protein and clinicopathologic features in nasopharyngeal carcinomas

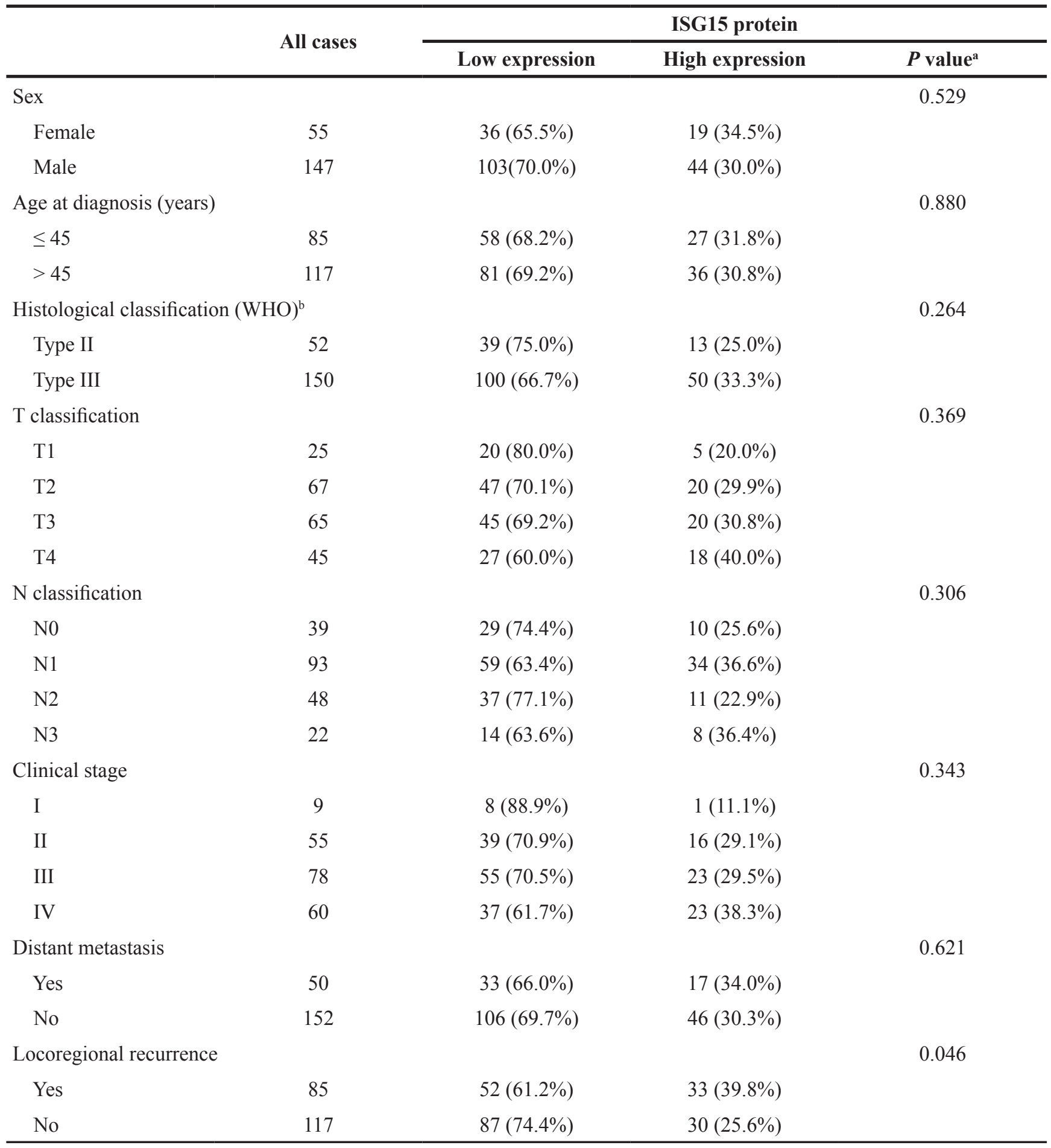

${ }^{a}$ Chi-square test;

${ }^{b}$ World Health Organization

5 -year survival in stage I-III (50.0 months vs. 56.2 months, $P=0.03$, Figure $3 \mathrm{E})$ and 3-year survival in stage IV $(27.2$ months vs. 32.6 months, $P=0.006$, Figure $3 \mathrm{~F}$ ). Thus, ISG15 expression is still a discriminating prognostic predictors in both stage I-III and stage IV. Taken together, these results demonstrated the significant prognostic power of ISG15 protein expression as a marker of poor outcome in NPC. 


\section{ISG15 promoted cancer stem cell-like properties in NPC cells}

To determine the functions of ISG15 in NPC, we established stable HONE1 and SUNE1 cell lines with ISG15 overexpression (Figure 4A) and performed a series of in vitro experiments with these cells. We found that the colonies and tumorspheres formed by in ISG15 overexpression cells are significantly increased in number and size than cells expressing control vector (Figure 4B and 4C). Next, we examined the CSC markers by real time PCR analysis. Expression levels of pluripotency-associated genes, including BMI1, c-MYC, NANOG, and KLF4 increased compared with their expression in cells expressing control vector (Figure 4D). Consistently, knockdown of ISG15 expression significantly inhibited colony and tumorsphere formation in HONE1 and another NPC cell line CNE2 (Figure 5A and 5B and 5C); knockdown of ISG15 expression also reduced the pluripotencyassociated gene expression levels when compared with the negative control (Figure 5D). To determine the tumorigenicity in vivo, we subcutaneously injected HONE1-ISG15 and vector-expressing cells into nude mice and found that ISG15 overexpression cells gave rise to more visible tumors than vector-expressing cells (Figure 6A and 6B). The estimated stem cell frequency is 1/1711 in ISG15 overexpression cells compared with $1 / 6146$ in the vector-expressing cells (Figure 6C and $6 \mathrm{D}, P=0.02)$. Taken together, these results indicated that induction of ISG15 stimulates the stemness properties of NPC.

\section{ISG15 conferred resistance to chemotherapy and radiation}

Because ISG15 induced stem-like properties and correlated with tumor recurrence and shorter survival, we further validated whether ISG15 may confer resistance to radiation and chemotherapy. As radiotherapy is the primary treatment regimen for NPC, we detected colony formation in cells after radiation exposure. Our results revealed that overexpression of ISG15 increased radioresistance in NPC cells (Figure 7A). The X-ray dose of IC50 in overexpression cells was higher than that in the vectors (Figure 7B. HONE1-ISG15 vs. vector, $4.61 \mathrm{~Gy}$ vs. $3.70 \mathrm{~Gy}, P<0.05$; SUNE1-ISG15 vs. vector, 3.47 Gy vs. $2.48 \mathrm{~Gy}, P<0.05)$. Moreover, cell viability assays were performed to evaluate DDP-induced apoptosis in ISG15 overexpression cells and vector-
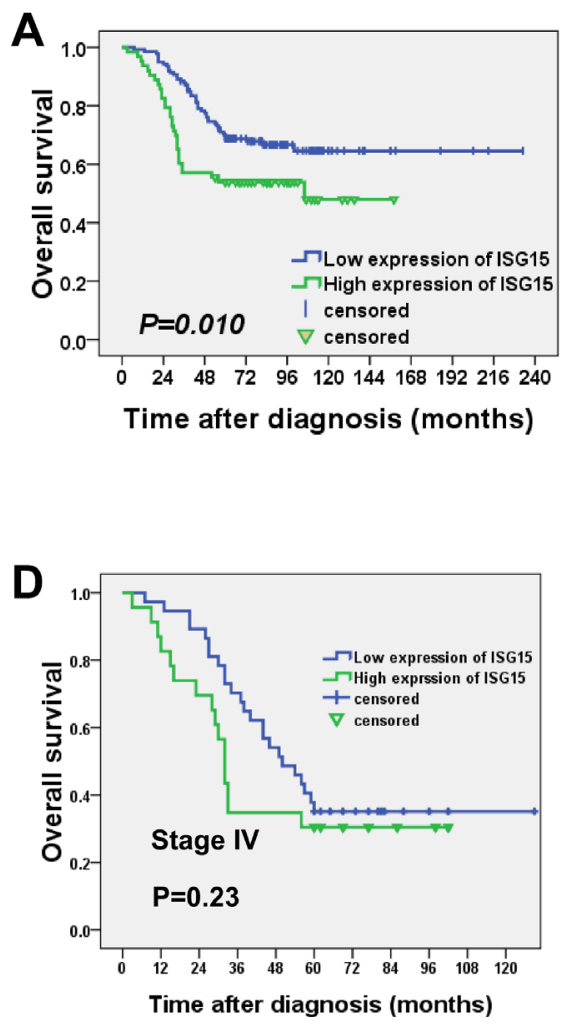
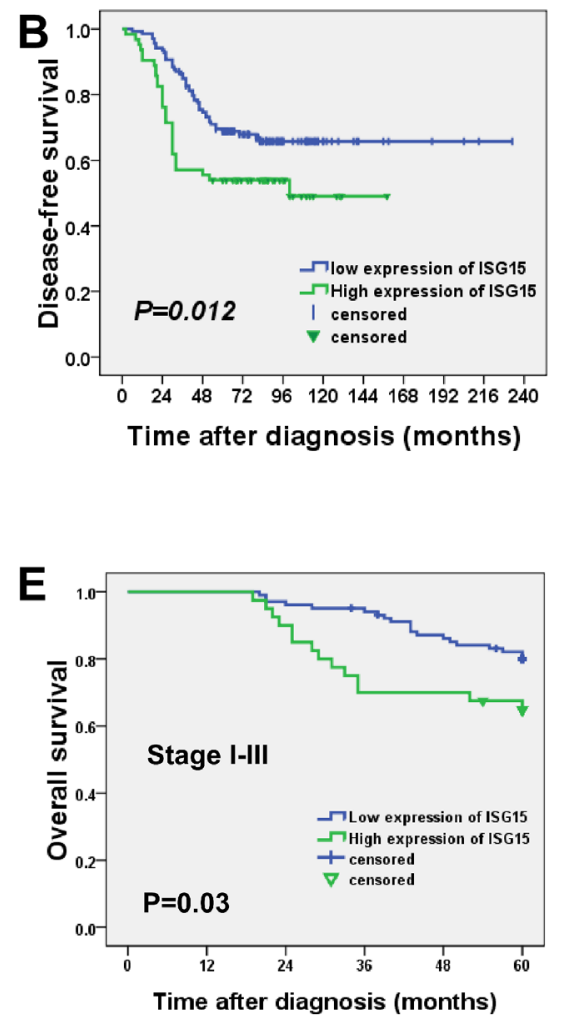
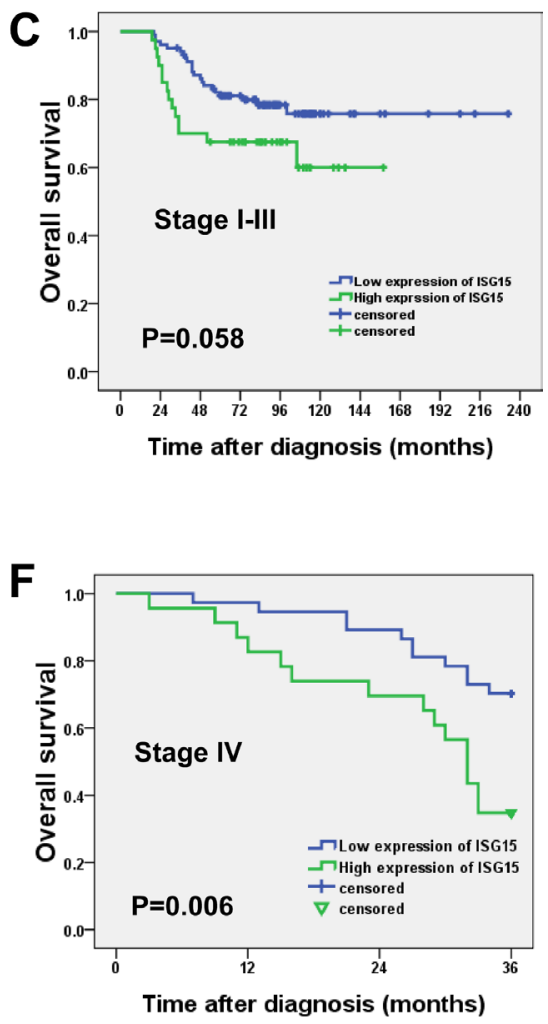

Figure 3: High expression of ISG15 indicated a shorter overall survival and disease-free survival in NPC patients. A. Kaplan-Meier survival analysis of ISG15 expression for overall survival and B. disease-free survival (long-rank test). C. Kaplan-Meier survival analysis of ISG15 expression for overall survival in stage I-III and D. stage IV. E. Further analysis for 5-year overall survival in stage I-III and F. 3-year overall survival in stage IV. 
Table 2: Univariate and multivariate analysis of different prognostic variables in 202 patients with nasopharyngeal carcinoma

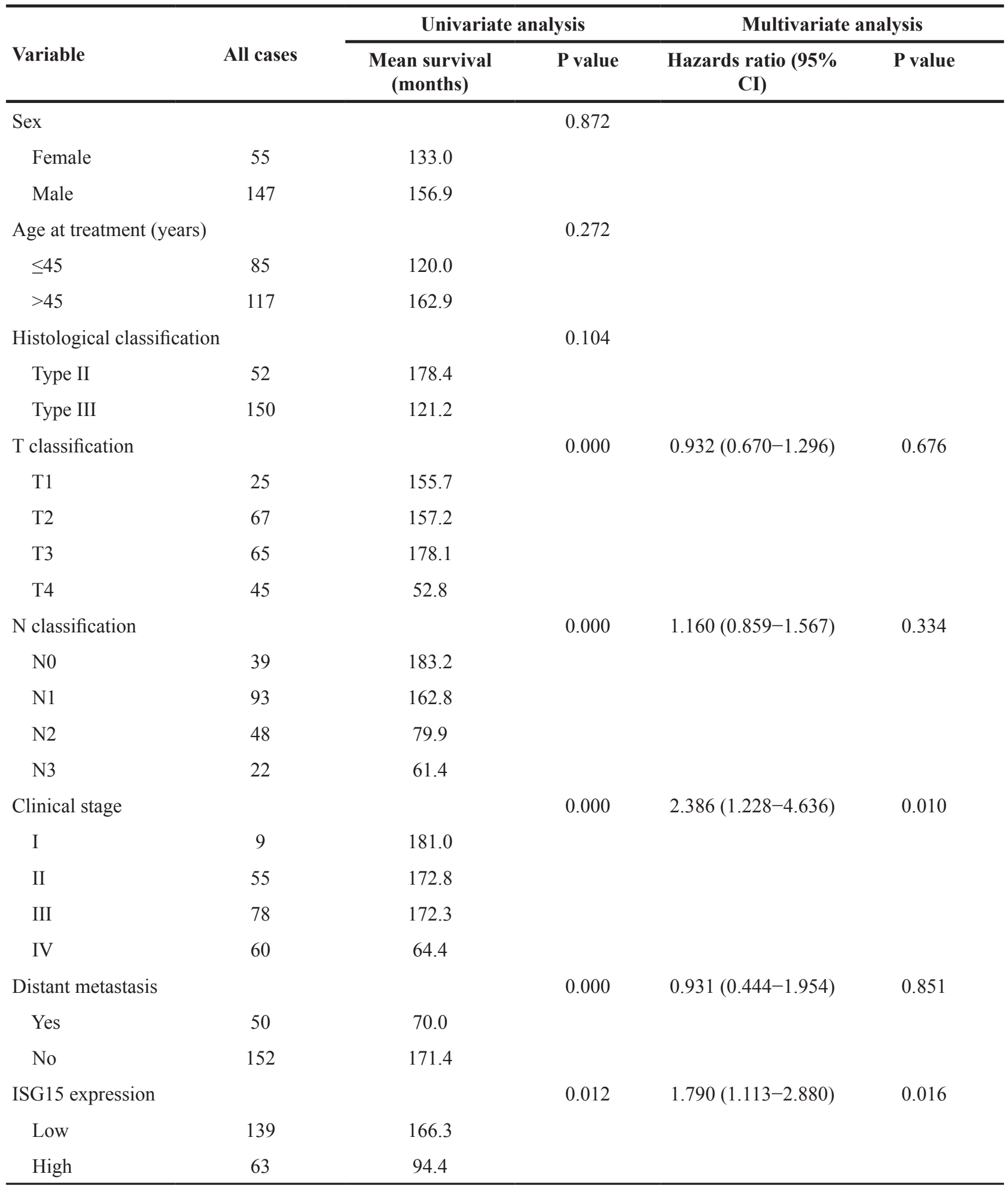


expressing cells. DDP-induced cell death was inhibited in ISG15 overexpression cells compared with vectorexpressing cells (Figure 7C). These results suggested that ISG15 conferred resistance to chemotherapy and radiation.

\section{DISCUSSION}

Recently, ISG15 has emerged as a promising oncoprotein elevated in various tumors [12-15]. However, it has also been reported that free ISG15 suppressed the growth of cancer cells via its immunomodulatory properties in vivo [18,21]. As a result, ISG15 was considered as a "double-edged sword protein" with both antitumor and protumor functions. However, its role in NPC remains unknown. Our study was the first to show that the expression of ISG15 was higher in NPC cell lines and NPC tissues compared with the immortalized NPECs and non-cancerous nasopharyngeal tissues. Moreover, high ISG15 level was associated with more tumor recurrence and indicated a shorter overall survival and disease-free survival in NPC patients. These observations indicated that ISG15 plays a protumor role in NPC development.

ISG15 is an interferon (IFN)- $\alpha / \beta$-inducible, ubiquitin-like intracellular protein. It can be induced by diverse microbial stimuli such as viral infection and LPS treatment $[22,23]$. The nasopharynx is the uppermost region of the pharynx, which is a transitional area between the nasal cavity and the pharynx. The unique anatomic site of NPC may imply a contributing role of the microenvironment in its pathogenesis [24,25]. EpsteinBarr virus (EBV) infection is a well-known predominant etiologic risk factor in NPC [26,27]. An intricate interplay of EBV with host matrix and genetic alteration in infected host cells is likely to be involved in the onset and progression of NPC $[25,28]$. Thus, it will be interesting

\section{A}

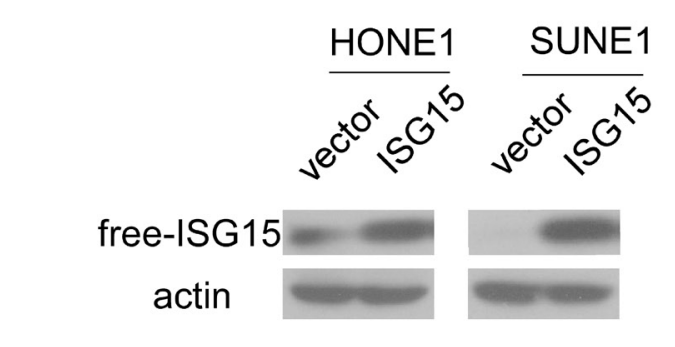

C
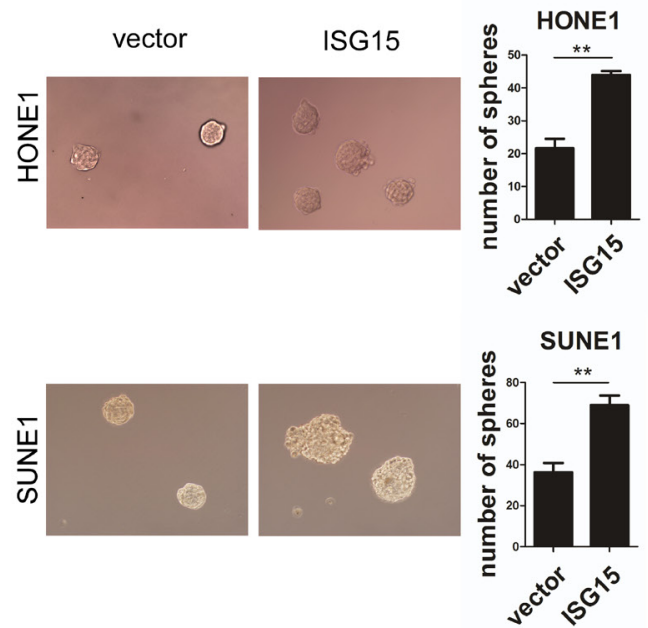

B
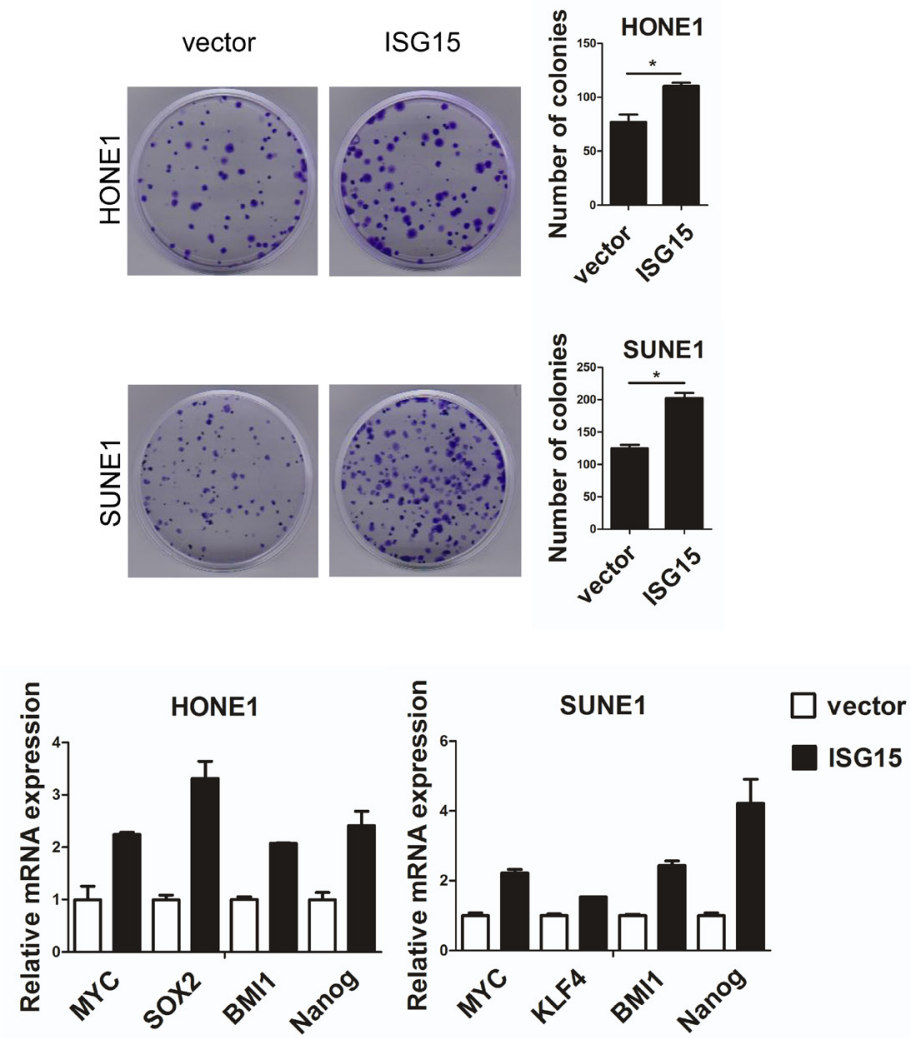

Figure 4: Overexpression of ISG15 promoted cancer stem cells-like property in NPC cells in vitro. A. Ectopic introduction of ISG15 into HONE1 and SUNE1 cell lines. B. Representative micrographs and quantification of colony formation and $\mathbf{C}$. tumorsphere formation in ISG15 overexpression or vector cells. D. Real-time PCR analysis of mRNA expression of pluripotency-associated markers in the indicated cells. 
A

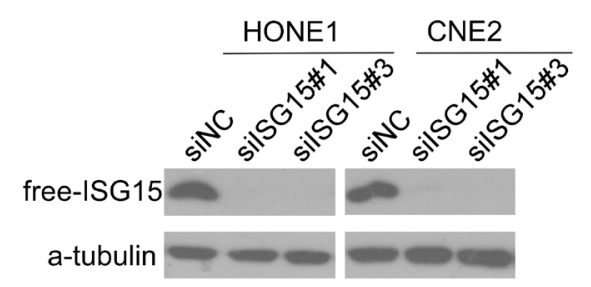

C
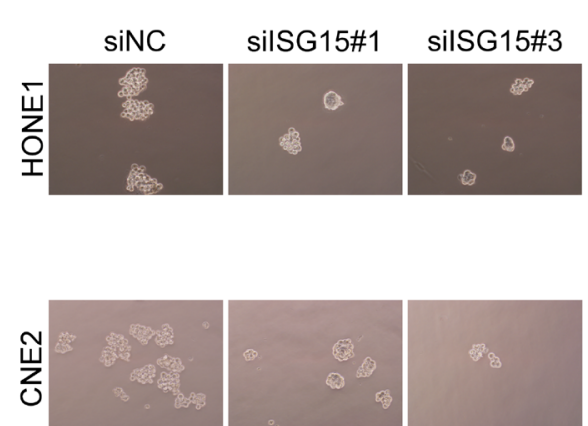

B
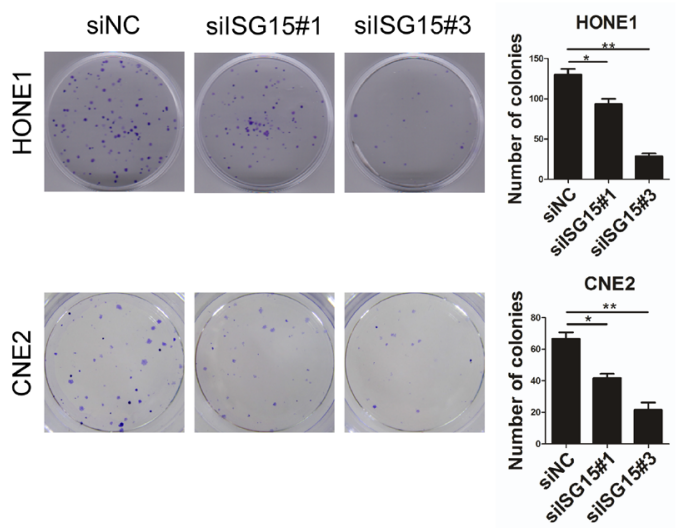

D

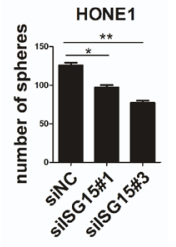

CNE2
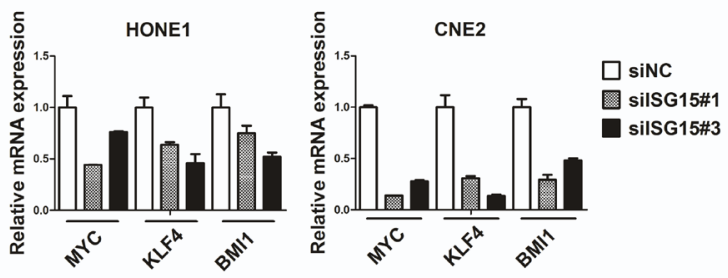

Figure 5: Knockdown of ISG15 attenuated cancer stem cells-like property in NPC cells in vitro. A. Knockingdown ISG15 resulted in reduced ISG15 protein in HONE1 and CNE2 cell lines. B. Representative micrographs and quantification of colony formation and C. tumorsphere formation in in ISG15 knock-down and control cells. D. PCR analysis of mRNA expression of pluripotency-associated markers in the indicated cells.
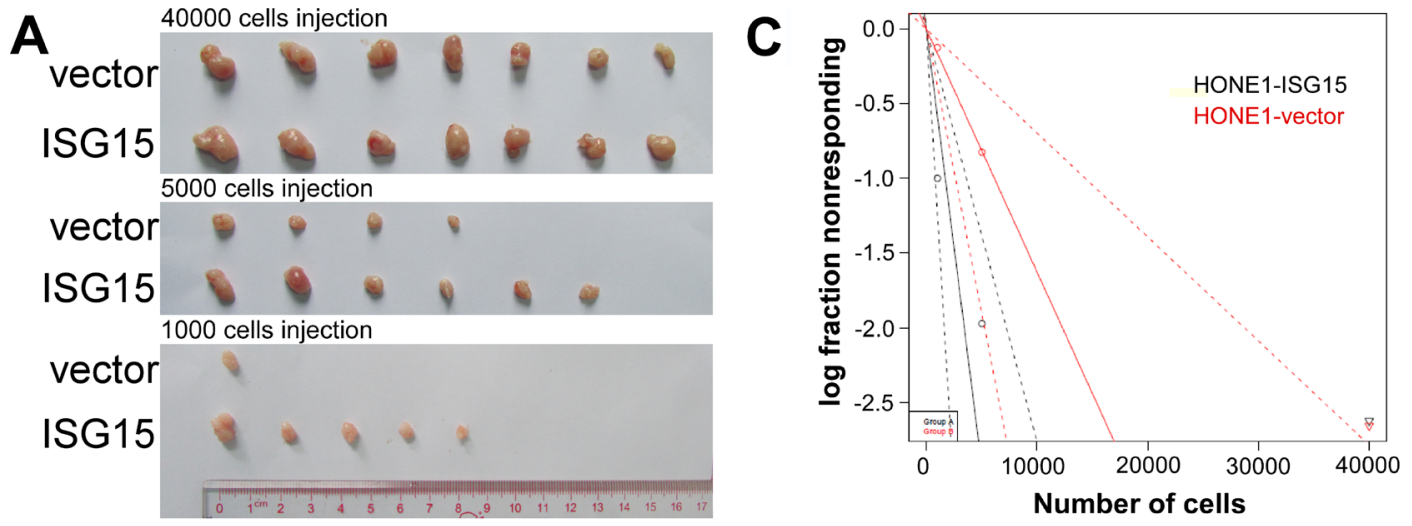

B

\begin{tabular}{|l|c|c|c|}
\hline & \multicolumn{3}{|c|}{ Tumor incidence } \\
\hline & 40000 & 5000 & 1000 \\
\hline vector & $7 / 7$ & $4 / 7$ & $1 / 8$ \\
\hline ISG15 & $7 / 7$ & $6 / 7$ & $5 / 8$ \\
\hline
\end{tabular}

D

\begin{tabular}{|l|c|c|c|c|c|}
\hline & \multicolumn{5}{|c|}{ Confidence intervals for 1/(stem cell frequency) } \\
\hline & Lower & Estimate & Upper & Chisq & P value \\
\hline vector & 14363 & 6146 & 2630 & 5.41 & 0.02 \\
\cline { 1 - 4 } ISG15 & 3619 & 1711 & 809 & & \\
\hline
\end{tabular}

Figure 6: Overexpression of ISG15 increased the tumorigenicity in vivo. A. and B. Tumor formation incidence. Mice were injected subcutaneously with the indicated numbers $\left(4 \times 10^{4}\right.$ to $1 \times 10^{3}$ cells $)$ of vector and ISG15 overexpression cells. C. and D. Confidence intervals for 1/(stem cell frequency). The data were analyzed with ELDA (Extreme Limiting Dilution Analysis). 
to investigate whether EBV infection contributes to overexpression of ISG15 in NPC.

Intracellular ISG15 exists in both free and conjugated pools [29]. Recent studies have revealed that intracellular free ISG15 promotes tumorigenesis and metastasis of hepatocellular cancer and breast cancer [12]. In this study, we showed that ISG15 possesses a capacity for driving stem cell-like characteristics in NPC. Ectopic introduction of ISG15 resulted in elevation of colony and sphere formation, a greater expression of pluripotent gene transcripts, and in vivo tumorigenic activity. In contrast, knockdown of ISG15 deregulated stem cell-like features. Parallel to the present results, it was also reported that TAMs secrete ISG15, which promotes CSC phenotypes in pancreatic ductal adenocarcinoma [13]. Our observation suggests that tumor cells expressing ISG15 enhance the CSC features of cancer cells.
Cancer stem cells (CSCs), a small population of cancer cells that possess the ability of self-renewal and differentiation, are thought to be responsible for tumor initiation and progression [30,31]. Recently, accumulating studies have demonstrated that the CSCs of NPC have played a vital role in tumor metastasis and relapse. For example, Qin et al. found that WNT5A promoted the stemness properties of NPC cells leading to metastasis and tumorigenesis [32]. It has also been reported that a stem cell-like side population in NPC was more resistant to chemotherapy and radiotherapy [33-35]. In the present study, overexpression of ISG15 in NPC cell lines enhances the resistance of radiation and DDP treatment. This is consistent with the clinically significant finding that high ISG15 expression was associated with more frequent tumor recurrence and shorter survival in NPC.

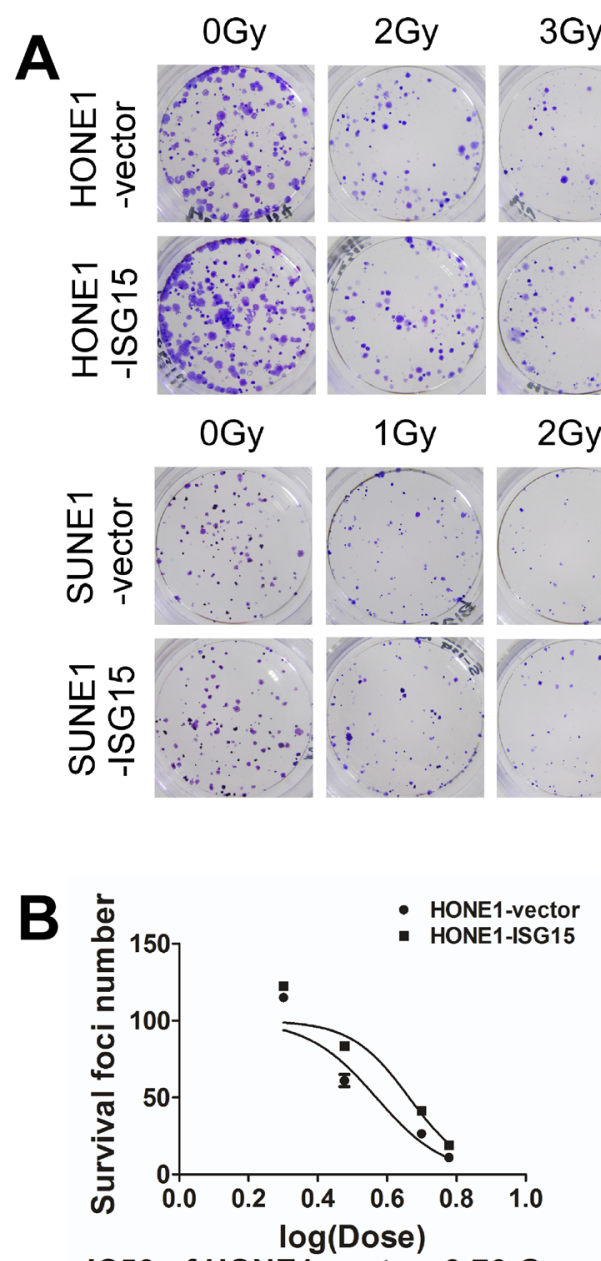

IC50 of HONE1-vector: $3.70 \mathrm{~Gy}$ IC50 of HONE1-ISG15: $4.61 \mathrm{~Gy}$
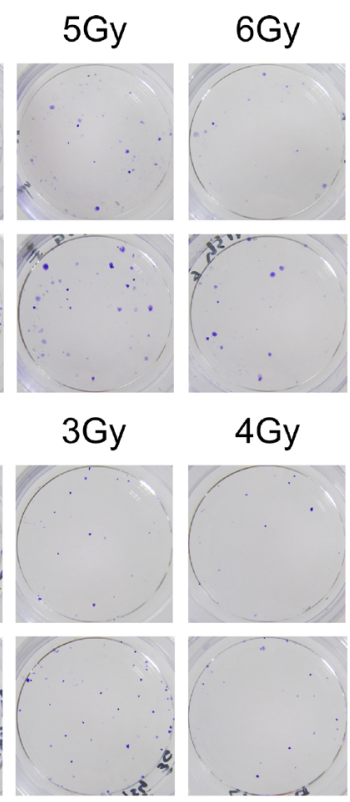

$4 \mathrm{~Gy}$
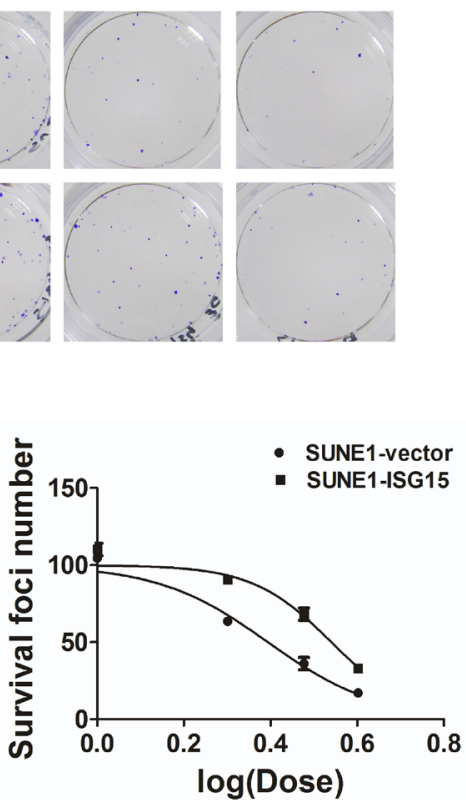

IC50 of SUNE1-vector: 2.48 Gy IC50 of SUNE1-ISG15: 3.47 Gy
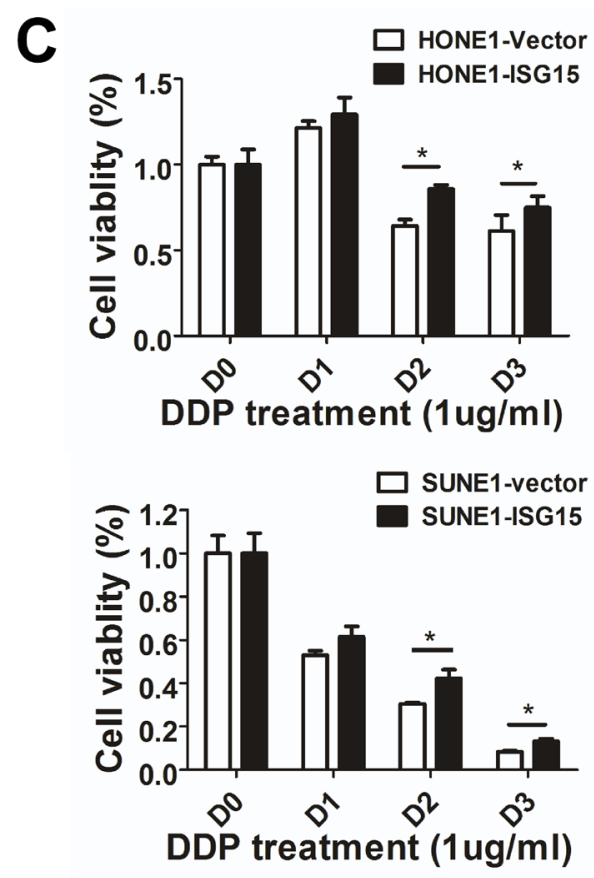

Figure 7: Overexpression of ISG15 enhanced NPC cell resistance to radiation and DDP treatment. A. Clonogenic survival assays show that ISG15 overexpression increased NPC cell radioresistance compared with the vector. B. X-ray dose of IC50 in ISG15 overexpression cells and vector-expressing cells. C. Cell viability assays show that ISG15 overexpression inhibited DDP-induced NPC cell death compared with the vector. 
In summary, ISG15 was up-regulated in NPC and predicted frequent tumor recurrence and poor outcome in patients. In vivo and in vitro studies revealed that ISG15 promotes CSC phenotype and radiation and chemotherapy resistance in NPC. These results demonstrated the significant prognostic power of ISG15 expression. ISG15 can serve as a biomarker with poor prognostic and a therapeutic target for NPC.

\section{MATERIALS AND METHODS}

\section{Patients and tissue specimens}

To compare the mRNA expression levels of ISG15 among non-cancerous nasopharyngeal mucosa and primary NPCs, biopsies were obtained at the Department of Otolaryngology \& Head Neck Surgery, Sun Yat-sen University Sun Yat-sen Memorial Hospital. NPC tissue microarray (TMA) analyses were performed as previously described [36, 37]. 209 cases of NPC with sufficient follow-up data were presented from the Department of Pathology, Sun Yat-sen University Cancer Center (SYSUCC).

\section{Cell culture}

Normal primary NPECs (NPEC03 and NPEC09) [38] and immortalized NPECs (NPEC1-Bmi1, NPEC2Bmi1) [39, 40] were cultured in Keratinocyte serumfree medium (Invitrogen, Carlsbad, CA, USA). The NPC cell lines (C666,CNE2, S18, S26, SUNE2, 5-8F, 6-10B, SUNE1, CNE1, HNE1, HK1, and HONE1) were cultured in RPMI 1640 (Invitrogen, Carlsbad, CA, USA) supplemented with $10 \%$ fetal bovine serum (FBS; Hyclone, Logan, UT, USA) in a humidified 5\% CO2 incubator at $37^{\circ} \mathrm{C}$.

\section{RNA isolation and reverse transcriptase PCR (RT-PCR) analysis}

Total RNA was extracted from the tissue specimens and NPC cell lines and NPECs using the TRIzol reagent (Invitrogen, Carlsbad, CA, USA), according to the manufacturer's instructions. The reverse transcriptase kit (Promega, Madison, Wisconsin, USA) was used to synthesize the complementary DNA (cDNA) from $2 \mu \mathrm{g}$ of the total RNA. qRT-PCR was performed using the Power SYBR Green qPCR SuperMix-UDG (Invitrogen, Carlsbad, CA, USA) to detect the mRNA level of the target genes using a LightCycler 480 II (Roche, Basel, Switzerland). $\beta$-actin was used as an internal control. The relative expression of target genes was normalized to the expression of $\beta$-actin, which yielded a2- $\Delta$ ct value. All reactions were performed in triplicate in three independent experiments. The sequences of the real-time PCR primers were as follows:
ISG15 sense: CGC AGA TCA CCC AGA AGA TCG

ISG15 anti-sense: TTC GTC GCA TTT GTC CAC CA

MYC sense: GCG TCC TGG GAA GGG AGA TCC

GGA GC

MYC anti-sense: TTG AGG GGC ATC GTC GCG

GGA GGC TG

KLF4 sense: ACG ATC GTG GCC CCG GAA AAG GAC C

KLF4 anti-sense: TGA TTG TAG TGC TTT CTG

GCT GGG CTC C

NANOG sense: CAG CCC CGA TTC TTC CAC

CAG TCC C

NANOG anti-sense: CGG AAG ATT CCC AGT

CGG GTT CAC C

SOX2 sense: GGG AAA TGG GAG GGG TGC

AAA AGA GG

SOX2 anti-sense: TTG CGT GAG TGT GGA TGG

GAT TGG TG

BMI1 sense: GCT GCC AAT GGC TCT AAT GAA

BMI1 anti-sense: TGC TGG GCA TCG TAA GTA TCT T

$\beta$-actin sense: CGC GAG AAG ATG ACC CAG AT AGA TG

$\beta$-actin anti-sense: GGG CAT ACC CCT CGT

\section{Western blotting analysis}

Cells were harvested and lysed in SDS sample buffer (62.5 mM Tris-HCl (pH 6.8), 3\% sodium dodecyl sulfate (SDS), 10\% glycerol, $50 \mathrm{mM}$ DL-dithiothreitol (DTT), and $0.1 \%$ bromophenol blue) with protease inhibitors (Roche, Indianapolis, IN, USA). The protein concentrations were determined by the BCA method (Pierce, Thermo Fisher Scientific Inc., Rockford, IL, USA). The proteins (10 ug) were separated by SDS-PAGE and transferred to a polyvinylidene difluoride membrane. Bovine serum albumin $(5 \%)$ in TBS-T $(1 \mathrm{~mol} / \mathrm{L}$ Tris- $\mathrm{HCl}$ $(\mathrm{pH} 7.5), 0.8 \% \mathrm{NaCl}$ and $0.1 \%$ Tween 20 ) was used to block the membrane. Then, the membrane was incubated with anti-ISG15 (Abcam, ab131119, Cambridge, MA, USA), anti- $\alpha$-tubulin (Abcam, ab126165, Cambridge, MA, USA), and anti- $\beta$-actin (Sigma-Aldrich, A5441, St.Louis, USA) antibodies at $4^{\circ} \mathrm{C}$ overnight. The blots were then treated with an HRP-conjugated secondary antibody (Pierce, Rockford, IL, USA).

\section{Immunohistochemistry}

The paraffin-embedded NPC sections were deparaffinized in xylene and an alcohol gradient to rehydrate the sections. Next, the sections were treated with a Citrate Antigen Retrieval Solution $(\mathrm{pH}=8.0)$ in a pressure cooker for $5 \mathrm{~min}$. Subsequently, 5\% bovine serum albumin (BSA) in PBS (25 mM Tris, $0.8 \% \mathrm{NaCl}$, 
$2.68 \mathrm{mM} \mathrm{KCl}(\mathrm{pH} 7.4)$ ) was added to block non-specific binding, and the sections were then incubated with a mouse monoclonal anti-ISG15 antibody (1:100, Abcam, ab131119, Cambridge, MA, USA) in a moist chamber overnight at $4{ }^{\circ} \mathrm{C}$. The secondary antibodies were incubated for $45 \mathrm{~min}$ at $37^{\circ} \mathrm{C}$ on the next day. Finally, the sections were incubated in 3, 3-diaminobenzidine for 2 min and counterstained with 10\% Mayer's hematoxylin before being dehydrated and mounted. As a negative control, the primary antibodies were replaced with normal rabbit serum.

Two independent pathologists who were blind to the clinical status of the patients scored the stained sections under a microscope. Semi-quantitative analysis was used to score the staining results. The intensity was scored as follows: 0 , negative staining; 1 , weak staining; 2, moderate staining; and 3, strong staining. According to the percentages of the positive stained areas, extent of staining was scored as follows: $1,<25 \%$ positive tumor cells; 2, 26-50\%; 3, 51-75\%; 4, 76-100\%. The final immunoreactivity score (IRS, 0 to 12 ) is the product of intensity score and the extent score.

\section{Establishment of stable ISG15 overexpressing cell lines}

Lentiviral particles were packaged and used for cell transduction according to the manufacturer's instructions (Invitrogen, San Diego, CA, USA). The HONE1 and SUNE1 cells were transfected with pLNCX2-ISG15 or pLNCX2 (Invitrogen, San Diego, CA, USA) using Lipofectamine 2000 (Invitrogen, San Diego, CA, USA) according to the manufacturer's protocol. After incubation for $24 \mathrm{~h}$, the selection reagent G418 (400 $\mu \mathrm{g} / \mathrm{mL}$; Invitrogen, San Diego, CA, USA) was added to select stably transfected clones. Selection was continued for 14 days.

\section{Transfection with siRNAs against ISG15}

SiRNAs targeting the mRNA of human ISG15 and the negative control (NC) (Ruibo Biotechnology Company, Guangzhou, China) were transfected into HONE1 and CNE2 cells using LipofectamineTM RNAi MAX reagent (Invitrogen, San Diego, CA, USA) according to the manufacturer's instructions. The siRNA sequences were as follows:

siISG15\#1

sense:

5'-UCCUGGUGAGGAAUAACAA dTdT-3' siISG15\#1 anti-sense: 5'-dTdT

AGGACCACUCCUUAUUGUU-3'

siISG15\#3

5'-GCACCGUGUUCAUGAAUCU dTdT-3' siISG15\#3 anti-sense:

sense:

5'-dTdT

\section{Colony formation assay}

Cells (300 cells per well) were plated evenly in 6-well plates and cultured for 10 days. After they were fixed with methanol for $10 \mathrm{~min}$, the colonies were stained with $0.5 \%$ crystal violet in $20 \%$ methanol and counted. Independent triplicate experiments were performed.

\section{Tumor sphere formation assays}

Cells (100 cells per well) were seeded in 6-well ultra-low cluster plates for 10 days. Spheres were cultured in DMEM/F12 serum-free medium (Invitrogen, San Diego, CA, USA) supplemented with 2\% B27 (Invitrogen, San Diego, CA, USA), $20 \mathrm{ng} / \mathrm{ml}$ EGF, $20 \mathrm{ng} / \mathrm{ml} \mathrm{bFGF}$, and $5 \mu \mathrm{g} / \mathrm{ml}$ insulin (Invitrogen, San Diego, CA, USA).

\section{Cell viability assays}

The CCK8 assay was used to measure the viability of the NPC cells. ISG15-overexpressing NPC cells were seeded onto a 96-well plate at a density of 500 cells per well. After $24 \mathrm{~h}, \mathrm{DDP}$ at $1 \mu \mathrm{g} / \mathrm{ml}$ was added into the cultures. The cells were incubated with $10 \mu \mathrm{l}$ CCK8 for $2 \mathrm{~h}$ at $37^{\circ} \mathrm{C}$, then cells were counted daily by reading the absorbance at $450 \mathrm{~nm}$.

\section{Tumorigenesis in vivo}

Female BALB/c (nu/nu) nude mice at 4-6 weeks of age were purchased from the Guangdong Medical Lab Animal Center Co. Ltd and maintained in microisolator cages. All animals were used in accordance with institutional guidelines, and the current experiments were approved by the Use Committee for Animal Care. For the tumorigenesis experiments, HONE1-vector and HONE1-ISG15 cells at different concentrations (1000, 5000, 40000 cells) in 100 $\mu l$ DMEM were injected subcutaneously into the flank of each mouse. Three weeks after inoculation, the tumors were observed and recorded, and the mice were euthanized. The data were analyzed with ELDA (Extreme Limiting Dilution Analysis) via http://bioinf.wehi.edu.au/sofeware/elda [41].

\section{Statistical analysis}

Student's t-test was used to compare two independent groups of data. ROC curve analysis was used to determine the cutoff value for dividing the patients into low and high ISG15 expression groups. Chi-squared tests were applied to analyze the relationship between ISG15 expression and clinicopathological status. KaplanMeier survival curves were plotted, and log-rank tests were performed. The significance of several variables for survival was analyzed using the Cox regression model in a multivariate analysis. A $P$ value $<0.05$ was considered statistically significant in all cases. 


\section{ACKNOWLEDGMENTS}

This study was supported by grants from the National Natural Science Foundation of China (grant nos. 81272950 and 81025014).

This work was also supported by Grant [2013]163 from Key Laboratory of Malignant Tumor Molecular Mechanism and Translational Medicine of Guangzhou Bureau of Science and Information Technology; Grant KLB09001 from the Key Laboratory of Malignant Tumor Gene Regulation and Target Therapy of Guangdong Higher Education Institutes.

\section{CONFLICTS OF INTEREST}

The authors have declared no conflicts of interest.

\section{REFERENCES}

1. Jemal, A, Bray, F, Center, MM, Ferlay, J, Ward, E and Forman, D. Global cancer statistics. CA Cancer J Clin. 2011;61:69-90.

2. Cao CN, Luo JW, Gao L, Yi JL, Huang XD, Wang K, Zhang SP, Qu Y, Li SY, Cai WM, Xiao JP, Zhang Z, Xu GZ. Clinical outcomes and patterns of failure after intensitymodulated radiotherapy for T4 nasopharyngeal carcinoma. Oral Oncol. 2013;49:175-81.

3. Ma BB, Hui EP, Chan AT. Systemic approach to improving treatment outcome in nasopharyngeal carcinoma: current and future directions. Cancer Sci. 2008;99:1311-8.

4. Li AC, Xiao WW, Shen GZ, Wang L, Xu AA, Cao YQ, Huang SM, Lin CG, Han F, Deng XW, Zhao C. Distant metastasis risk and patterns of nasopharyngeal carcinoma in the era of IMRT: long-term results and benefits of chemotherapy. Oncotarget. 2015;6:24511-21. doi: 10.18632/oncotarget.4312.

5. Tang LL, Guo R, Zhou G, Sun Y, Liu LZ, Lin AH, Mai $\mathrm{H}$, Shao J, Li L, Ma J. Prognostic value and staging classification of retropharyngeal lymph node metastasis in nasopharyngeal carcinoma patients treated with intensitymodulated radiotherapy. PLoS One. 2014; 9:e108375.

6. Wang W, Feng M, Fan Z, Li J, Lang J. Clinical outcomes and prognostic factors of 695 nasopharyngeal carcinoma patients treated with intensity-modulated radiotherapy. Biomed Res Int. 2014;2014:814948.

7. Haas AL, Ahrens P, Bright PM, Ankel H. Interferon induces a 15-kilodalton protein exhibiting marked homology to ubiquitin. J Biol Chem. 1987;262: 11315-23.

8. Ketscher L, Hannß R, Morales DJ, Basters A, Guerra S, Goldmann T, Hausmann A, Prinz M, Naumann R, Pekosz A, Utermöhlen O, Lenschow DJ, Knobeloch KP. Selective inactivation of USP18 isopeptidase activity in vivo enhances ISG15 conjugation and viral resistance. Proc Natl Acad Sci U S A. 2015;112:1577-82.
9. Rahnefeld A, Klingel K, Schuermann A, Diny NL, Althof N, Lindner A, Bleienheuft P, Savvatis K, Respondek D, Opitz E, Ketscher L, Sauter M, Seifert U, et al. Ubiquitinlike protein ISG15 (interferon-stimulated gene of $15 \mathrm{kDa}$ ) in host defense against heart failure in a mouse model of virusinduced cardiomyopathy. Circulation. 2014;130:1589-600.

10. Zhang X, Bogunovic D, Payelle-Brogard B, FrancoisNewton V, Speer SD, Yuan C, Volpi S, Li Z, Sanal O, Mansouri D, Tezcan I, Rice GI, Chen C, et al. Human intracellular ISG15 prevents interferon-alpha/beta overamplification and auto-inflammation. Nature. 2015. 517: 89-93.

11. Radoshevich L, Impens F, Ribet D, Quereda JJ, Nam Tham T, Nahori MA, Bierne H, Dussurget O, Pizarro-Cerdá J, Knobeloch KP, Cossart P. ISG15 counteracts Listeria monocytogenes infection. Elife. 2015;4:e06848.

12. Li C, Wang J, Zhang H, Zhu M, Chen F, Hu Y, Liu H, Zhu H. Interferon-stimulated gene 15 (ISG15) is a trigger for tumorigenesis and metastasis of hepatocellular carcinoma. Oncotarget. 2014;30:8429-41. doi: 10.18632/ oncotarget.2316.

13. Sainz B Jr, Martín B, Tatari M, Heeschen C, Guerra S. ISG15 is a critical microenvironmental factor for pancreatic cancer stem cells. Cancer Res. 2014;74:7309-20.

14. Kiessling A, Hogrefe C, Erb S, Bobach C, Fuessel S, Wessjohann L, Seliger B. Expression, regulation and function of the ISGylation system in prostate cancer. Oncogene. 2009;28:2606-20.

15. Bektas N, Noetzel E, Veeck J, Press MF, Kristiansen G, Naami A, Hartmann A, Dimmler A, Beckmann MW, Knüchel R, Fasching PA, Dahl E. The ubiquitin-like molecule interferon-stimulated gene 15 (ISG15) is a potential prognostic marker in human breast cancer. Breast Cancer Res. 2008;10:R58.

16. Andersen JB, Hassel BA.The interferon regulated ubiquitinlike protein, ISG15, in tumorigenesis: friend or foe? Cytokine Growth Factor Rev. 2006,17:411-21.

17. Huang YF, Bulavin DV. Oncogene-mediated regulation of p53 ISGylation and functions. Oncotarget. 2014;30:580818. doi: 10.18632/oncotarget.2199.

18. Yeh YH, Yang YC, Hsieh MY, Yeh YC, Li TK. A negative feedback of the HIF-1alpha pathway via interferonstimulated gene 15 and ISGylation. Clin Cancer Res. 2013;19: 5927-39.

19. Feng Q1, Sekula D, Guo Y, Liu X, Black CC, Galimberti F, Shah SJ, Sempere LF, Memoli V, Andersen JB, Hassel BA, Dragnev K, Dmitrovsky E. UBE1L causes lung cancer growth suppression by targeting cyclin D1. Mol Cancer Ther. 2008,7:3780-8.

20. Burks J, Reed RE, Desai SD. Free ISG15 triggers an antitumor immune response against breast cancer: a new perspective. Oncotarget. 2015;6:7221-31. doi: 10.18632/ oncotarget.3372. 
21. Villarreal DO, Wise MC, Siefert RJ, Yan J, Wood LM, Weiner DB. Ubiquitin-like Molecule ISG15 Acts as an Immune Adjuvant to Enhance Antigen-specific CD8 T-cell Tumor Immunity. Mol Ther. 2015;10: 1653-62.

22. Zhao C, Collins MN, Hsiang TY, Krug RM. Interferoninduced ISG15 pathway: an ongoing virus-host battle. Trends Microbiol. 2013; 21: 181-6.

23. Bogunovic D, Boisson-Dupuis S, Casanova JL. ISG15: leading a double life as a secreted molecule. Exp Mol Med. 2013;45:e18.

24. Li Z, Duan Y, Cheng S, Chen Y, Hu Y, Zhang L, He J, Liao Q, Yang L, Sun LQ. EBV-encoded RNA via TLR3 induces inflammation in nasopharyngeal carcinoma. Oncotarget. 2015;6:24291-303. doi: 10.18632/oncotarget.4552.

25. Gourzones C, Barjon C, Busson P. Host-tumor interactions in nasopharyngeal carcinomas. Semin Cancer Biol. 2012;22:127-36.

26. Raab-Traub N. Epstein-Barr virus in the pathogenesis of NPC. Semin Cancer Biol. 2002;12:431-41.

27. Wei WI, Sham JS. Nasopharyngeal carcinoma. Lancet, 2005; 365: 2041-54.

28. Tsao SW, Yip YL, Tsang CM, Pang PS, Lau VM, Zhang G, Lo KW. Etiological factors of nasopharyngeal carcinoma. Oral Oncol. 2014;50:330-38.

29. Tsao SW, Yip YL, Tsang CM, Pang PS, Lau VM, Zhang G, Lo KW. Etiological factors of nasopharyngeal carcinoma. Oral Oncol. 2014;50:330-38.

30. Morrison S J, Kimble J. Asymmetric and symmetric stemcell divisions in development and cancer. Nature. 2006, 441:1068-74.

31. Li Y, Laterra J. Cancer stem cells: distinct entities or dynamically regulated phenotypes? Cancer Res. 2012, 72: 576-80.

32. Qin L, Yin YT, Zheng FJ, Peng LX, Yang CF, Bao YN, Liang YY, Li XJ, Xiang YQ, Sun R, Li AH, Zou RH, Pei XQ, et al. WNT5A promotes stemness characteristics in nasopharyngeal carcinoma cells leading to metastasis and tumorigenesis. Oncotarget. 2015;6:10239-52. doi: 10.18632/oncotarget.3518.

33. Wang J, Guo LP, Chen LZ, Zeng YX, Lu SH. Identification of cancer stem cell-like side population cells in human nasopharyngeal carcinoma cell line. Cancer Res. 2007;67: 3716-24.
34. Wang WJ, Wu SP, Liu JB, Shi YS, Huang X, Zhang QB, Yao KT. MYC regulation of CHK1 and CHK2 promotes radioresistance in a stem cell-like population of nasopharyngeal carcinoma cells. Cancer Res. 2013;73:1219-31.

35. Yang CF, Peng LX, Huang TJ, Yang GD, Chu QQ, Liang YY, Cao X, Xie P,Zheng LS, Huang HB, Cai MD, Huang JL, Liu RY, et al. Cancer stem-like cell characteristics induced by EB virus-encoded LMP1 contribute to radioresistance in nasopharyngeal carcinoma by suppressing the p53-mediated apoptosis pathway. Cancer lett. 2014;344: 260-71.

36. Li XJ, Ong CK, Cao Y, Xiang YQ, Shao JY, Ooi A, Peng LX, Lu WH, Zhang Z, Petillo D, Qin L, Bao YN, Zheng FJ, et al. Serglycin is a theranostic target in nasopharyngeal carcinoma that promotes metastasis. Cancer Res. 2011;71:3162-72.

37. Li XJ, Peng LX, Shao JY, Lu WH, Zhang JX, Chen S, Chen ZY, Xiang YQ, Bao YN, Zheng FJ, Zeng MS, Kang TB, Zeng YX, et al. As an independent unfavorable prognostic factor, IL-8 promotes metastasis of nasopharyngeal carcinoma through induction of epithelial-mesenchymal transition and activation of AKT signaling. Carcinogenesis. 2012;33:1302-1309.

38. Liao WT, Wang HM, Li MZ, Song LB, Zhang L, Mai HQ, Xia YF, Zheng ML, Fu LW, Zeng YX, Zeng MS. Establishment of three-dimensional culture models related to different stages of nasopharyngeal carcinogenesis [Article in Chinese]. Ai Zheng. 2005;24:1317-21.

39. Song LB, Li J, Liao WT, Feng Y, Yu CP, Hu LJ, Kong QL, Xu LH, Zhang X, Liu WL, Li MZ, Zhang L, Kang TB, et al. The polycomb group protein Bmi-1 represses the tumor suppressor PTEN and induces epithelial-mesenchymal transition in human nasopharyngeal epithelial cells. J Clin Invest. 2009;119: 3626-36.

40. Wang HB, Zhang H, Zhang JP, Li Y, Zhao B, Feng GK, Du Y, Xiong D, Zhong Q, Liu WL, Du H, Li MZ, Huang WL, et al. Neuropilin 1 is an entry factor that promotes EBV infection of nasopharyngeal epithelial cells. Nat Commun. 2015;6:6240.

41. Hu, Y, Smyth, GK. ELDA: Extreme limiting dilution analysis for comparing depleted and enriched populations in stem cell and other assays. J Immunol Methods. 2009; 347: 70-78. 